\title{
Fast and frugal framing effects?
}

Article

Accepted Version

McCloy, R. A., Beaman, C. P., Frosch, C. A. and Goddard, K. (2010) Fast and frugal framing effects? Journal of Experimental Psychology: Learning, Memory \& Cognition, 36 (4). pp. 1043-1052. ISSN 1939-1285 doi: https://doi.org/10.1037/a0019693 Available at https://centaur.reading.ac.uk/5758/

It is advisable to refer to the publisher's version if you intend to cite from the work. See Guidance on citing.

To link to this article DOI: http://dx.doi.org/10.1037/a0019693

Publisher: American Psychological Association.

Publisher statement: This article may not exactly replicate the final version published in the APA journal. It is not the copy of record.

All outputs in CentAUR are protected by Intellectual Property Rights law, including copyright law. Copyright and IPR is retained by the creators or other copyright holders. Terms and conditions for use of this material are defined in the End User Agreement.

\section{www.reading.ac.uk/centaur}

\section{CentAUR}

Central Archive at the University of Reading

Reading's research outputs online 


\title{
Fast and Frugal Framing Effects?
}

\author{
Rachel McCloy ${ }^{1}$ \\ C. Philip Beaman ${ }^{1,2}$ \\ Caren A. Frosch ${ }^{1}$ \\ Kate Goddard ${ }^{1}$
}

\author{
${ }^{1}$ School of Psychology \& Clinical Language Sciences \\ University of Reading \\ ${ }^{2}$ Centre for Integrative Neuroscience and Neurodynamics \\ University of Reading
}

Running Head: FAST AND FRUGAL FRAMING EFFECTS

BRIEF REPORT: 5, 000 words.

Correspondence can be addressed to Rachel McCloy or Philip Beaman at:

School of Psychology \& Clinical Language Sciences, University of Reading, Earley

Gate, Whiteknights, Reading, UK, RG6 6AL

Email: r.a.mccloy@reading.ac.uk or c.p.beaman@reading.ac.uk

Telephone: +44 (0) 1183786027 or +44 (0) 1183787637

Fax: +44 (0) 1183786715 


\begin{abstract}
Three experiments examine whether simple pair-wise comparison judgments, involving the "recognition heuristic" (Goldstein \& Gigerenzer, 2002), are sensitive to implicit cues to the nature of the comparison required. Experiments $1 \& 2$ show that participants frequently choose the recognized option of a pair if asked to make "larger" judgments but are significantly less likely to choose the unrecognized option when asked to make "smaller" judgments. Experiment 3 demonstrates that, overall, participants consider recognition to be a more reliable guide to judgments of a magnitude criterion than lack of recognition and that this intuition drives the framing effect. These results support the idea that, when making pair-wise comparison judgments, inferring that the recognized item is large is simpler than inferring that the unrecognized item is small.
\end{abstract}

125 words 
The recognition heuristic, one of a number of suggested "fast and frugal" heuristics, provides the following rule-of-thumb for inferences with respect to an unknown criterion: "If one of two objects is recognized and the other is not, then infer that the recognized object has the higher value with respect to the criterion " (Goldstein \& Gigerenzer, 2002, p. 76). So, for example, if a participant is asked to judge which of two cities has the larger population, and they recognize only one of the cities, following the recognition heuristic leads them to choose the recognized city. Recognition works as a strategy in cases where the probability of recognition is influenced by a mediator variable which itself reflects the "real" but inaccessible criterion (Goldstein \& Gigerenzer, 2002). For example, the mediating variable for many such choices might be the number of times something (i.e., a city) has appeared in newspaper reports. Larger cities are more likely to be encountered (e.g., mentioned in newspaper reports) and hence more likely to be recognized. In this example, recognition therefore provides a cue to size.

The recognition heuristic has been widely investigated in magnitude inference and performance prediction tasks, particularly in sporting domains (Bennis \& Pachur, 2006; Pachur \& Biele, 2007; Serwe \& Frings, 2006) where the requirement to assess the biggest, the fastest, or the most promising is self-evident. For the sake of simplicity, we will talk in terms of "magnitude judgments" but note that the recognition heuristic is much more generally applicable, being a tool for making inferences about some unknown criterion. Where this criterion is susceptible (at least in principle) to quantification, these inferences can be spoken of in terms of judgments of "magnitude" across that criterion. 
In the cities task, and in many other tasks in which the recognition heuristic has been tested, the question asks for the larger, or more highly-valued, item along the criterion or magnitude in question. Under these circumstances, a possible implementation of the recognition heuristic inference rule could be of the form: Large $(X)$ if Recognized $(X)$. Thus, when asked "which is larger?" a response of $\mathrm{X}$ is compatible with the information given in the question (i.e., that "largeness" is important). An alternative articulation of the rule, however, is that the inference is drawn across the pair. Formally, Larger $(X, Y)$ if Recognized $(X)$ and $\neg$ Recognized $(Y)$ and it is this implication which seems to have been intended by Goldstein and Gigerenzer (2002). The two variants are equally responsive to the structure of the environment in that, if the direction of the correlation between recognition and criterion is evaluated (as suggested by Goldstein \& Gigerenzer, 2002, p. 76), they can be reversed equally easily, and the unrecognized option selected if this correlation is negative. Substituting Small for Large in the above inference rules, for example, produces the following inference rules: Small $(X)$ if Recognized $(X)$ and Smaller $(X, Y)$ if Recognized $(X)$ and $\neg$ Recognized $(Y)$. Either rule would account for the apparent "reversal" of the recognition heuristic when the criterion-recognition correlation is negative, as reported by Oppenheimer (2003). Nevertheless, these contrasting implementations of the heuristic raise the possibility that a framing effect (Tversky \& Kahneman, 1981) may occur in recognition-based choices if the question, rather than the criterion-recognition correlation, is shifted.

Framing effects are common across a wide range of decision making tasks (e.g., Kuhberger, 1995, 1998). They occur where choices alter based on how the options are 
described even though the information given in the descriptions is logically equivalent (Johnson-Laird \& Shafir, 1993). The 2-AFC cities task can be placed within this context. Least (which is smallest?) and greatest (which is biggest?) framings of the judgment are logically equivalent for a $2-\mathrm{AFC}$ task, since $\mathrm{X}>\mathrm{Y}$ necessarily entails that $\mathrm{Y}<\mathrm{X}$. However, two logically equivalent statements (A and B) about a choice problem are only informationally equivalent if there is no choice relevant background condition, which a listener can infer from the speaker's choice to present either A or B to the listener (Sher \& Mackenzie, 2006). Otherwise, the listener infers that the speaker's decision to use either $\mathrm{A}$ or $\mathrm{B}$ as a means of presenting information reveals something about the speaker's interests and requirements (Grice, 1975).

Could this analysis apply to recognition-driven inference, and what would the consequences for adaptive heuristics be? Specifically, if the question is altered from "which of two objects has the highest value (which is largest)" to "which object has the lowest value (which is smallest)" an inference made across the pair of items provides direct information about the unrecognized item $(\operatorname{Larger}(X, Y))$. The two queries are then equivalent and the unrecognized item should be chosen. If, however, the inference typically drawn is Large $(X)$ if Recognized $(X)$ that is, if the individual chooses to focus primarily or only upon the recognized item, then the two queries are not directly equivalent. Arguably, further work is necessary to establish Small $(Y)$ if $\neg$ Recognized $(Y)$ and choice of the unrecognized item may be much less common.

The classical statement of the recognition heuristic (Goldstein \& Gigerenzer, 2002, p. 76) assumes that comparison tasks are solved by inferring the relationship between the two items. In this case the logical equivalence of 2-AFC lesser and greater 
judgments should be transparent and there should be a reversal in choices when a least question is substituted for a greatest question. There should be invariance in the usage of the heuristic and hence no framing effect. Conversely, if the judgments are based upon an inference about the recognized item only, then more choices of the recognized item with the greater question should be made than choices of the unrecognized item with the lesser question. Note that, in a classic "framing" manipulation, choice shifts between two options based on the presentation of those options. We do not expect participants to abandon recognition entirely as a cue, rather, given a different question framing, we wish to determine whether heuristic usage - defined here as using recognition as a cue according to the pair-wise inference rule Larger $(X, Y)$ if Recognized $(X)$ and $\neg$ Recognized $(Y)$ - declines despite the logical equivalence of the query.

\section{Experiment 1}

Method.

Participants. 92 volunteers (54 men, 38 women) participated. Average age was 25 years (range 17-62). The participants were divided into two groups: a "larger" $(\mathrm{n}=50)$ and a "smaller" framing group $(\mathrm{n}=42)$.

Materials and Design. The materials used in this experiment were based on those used by Oppenheimer (2003). The names of 10 English towns were paired with the names of 10 fictional towns (see Appendix A). The English towns were selected from a list of 
towns with football teams in the Championship ${ }^{1}$, and each was paired with three different fictional towns, giving 30 test pairs. English towns or cities whose soccer teams played in the Championship ${ }^{2}$, were chosen as their names would thus be familiar to the participants without being considered a large or major city. Large cities in the UK (e.g., Liverpool, Manchester) tend to have soccer teams in the Premier League rather than the Championship ${ }^{3}$. In addition, two groups of filler items were created. The first group consisted of 10 pairs of real towns and cities taken from a list of 8 (four international towns/cities, e.g., Limerick, and four English towns, e.g., Bradford). The second type of filler item consisted of pairs of the fictional towns. Participants each received 9 pairs of this type ${ }^{4}$. Each participant received 49 choice pairs in total, of which 30 were of the critical recognition heuristic type. The order of presentation of these pairs was randomized across participants.

Procedure. Participants were presented with a four-page experimental booklet. They were told that they would be presented with pairs of names of towns. The "larger" framing group was told that their task was to circle the town with the largest population in each pair. The "smaller" group was asked to circle the town with the smallest population. Participants were given one minute to complete the task ${ }^{5}$. In order to encourage them to work quickly, participants were given time updates at 15 -second intervals. On completion of the first part of the task participants were given a list of all

\footnotetext{
${ }^{1}$ As current in the 2003-4 season.

${ }^{2}$ Formerly known as the First Division, the Championship is the second tier soccer league.

${ }^{3}$ Large cities often have more than one soccer team so towns with teams in both the Championship and the Premier League (e.g., Birmingham) were also excluded.

${ }^{4}$ There should have been 10 pairs of this type but, due to a printing error, participants only received 9 pairs.

${ }^{5}$ It seems reasonable to assume that participants will be more inclined to employ fast and frugal heuristics where the situation requires them to be fast or frugal, hence we employed a degree of time pressure for people's judgments.
} 
of the towns used in the experiment (both real and fictional) and asked to circle those they recognized prior to the experiment.

Results.

Some participants did not complete all 49 choices in the allotted time and some either failed to recognize a real town name, or erroneously recognized a fictional town name. Therefore, we calculated for each participant: (a) the number of times they could have used the recognition heuristic (i.e., where one item in a pair is recognized and the other is not), (b) the number of times they did use the recognition heuristic. The second figure divided by the first gives the proportion of responses consonant with the recognition heuristic. Figure 1 shows the proportionate use of decision-processes consistent with the recognition heuristic for each individual in the greater framing (upper panel) and the lesser framing (lower panel) of the choice task. For the "greater" framing group, this is the proportion of responses where the recognized item was chosen. For the "lesser" framing group, this is the proportion of responses where the unrecognized item was chosen.

\section{FIGURE ONE ABOUT HERE}

Comparison of the groups shows that the incidence of choices consistent with the recognition heuristic was significantly greater in the "larger" (mean proportion heuristic usage 62\%) than in the "smaller" framing (mean proportion $53 \%$ ), $t=3.31, d f$ $=90, p<0.001$ (1-tailed). For the larger framing group, a one sample t-test further 
showed that, by participant, the proportion of responses consistent with the recognition heuristic was significantly greater than would be expected by chance, $t=3.55, d f=49, p$ $=.001^{6}$. In contrast, amongst the "smaller" framing group one sample t-test, by participant, failed to show any significant difference from chance, $t=1.0, d f=41, p=$ .34 .

Discussion

Experiment 1 shows that participants were less likely to base their judgments on recognition when asked which of two cities was the smaller than when asked which of two cities was the larger. Although they chose the city they recognized more often than chance for the "larger" question, they did not choose the unrecognized city more often than chance for the "smaller" question, as predicted by choice based on a direct inference about the relationship between the two items. Instead, the existence of a framing effect in people's usage of the recognition heuristic is consistent with an inference that is primarily directed at the recognized item (an item-based inference).

\section{Experiment 2.}

In running Experiment 1 we observed that, on debrief, participants sometimes claimed that they had used the foreign sounding names of the cities as a cue. For example, Rhavadran and Heingjing were reported as sounding Indian and Chinese respectively, both (from a UK perspective) large, and heavily-populated regions located

\footnotetext{
${ }^{6}$ In this and all subsequent analyses, the $p$-values reported for all $t$-tests are 2-tailed unless stated otherwise.
} 
on a different continent. It was therefore reasonable for UK participants to suppose that these unfamiliar cities were relatively large but unknown to them by virtue of distance. Reasoning of this kind may have affected choice decisions when these items were involved. It is unlikely to affect the appearance of the framing effect since both groups were presented with the same stimuli but, to be sure, we re-ran Experiment 1 using a different domain, a different set of stimuli and a different judgment task. In addition to moving away from any potential problems with the "Cities" materials, moving to studying recognition within a new domain helps to establish the generality of any findings. We chose judgments of the relative wealth of individuals as our new domain. If asked which of two people is the wealthier, it may be reasonable to choose recognized (famous) names over unrecognized (unknown) names, i.e., to apply the recognition heuristic. Each year, the Sunday Times newspaper in the United Kingdom prints an ordered list of the 1000 richest people in the country, alongside several additional lists (e.g., 100 richest people under 30 years old). As the wealth of the people on this list comes from a wide range of sources (e.g., business, inheritance, entertainment) there is scope for wide variation in recognition, not only across the people named, but also across participants in any experiment (depending on their areas of interest). This makes it a very rich domain in which to study the impact that recognition has on judgments of relative wealth.

Method

Participants and Procedure. 80 volunteers (28 men, 32 women) participated. Average age was 23 years (range 18-54). They were divided into a "richer" $(\mathrm{n}=40)$ and a 
"poorer" framing group $(n=40)$. The procedure was essentially identical to that of Experiment 1. Participants were presented with a booklet containing 60 pairs of names taken from the Sunday Times Rich List 2005 and were asked to circle who out of each pair was the richest ("richer" framing group) or poorest (“poorer" framing group). Participants had 90 seconds to complete the task, with updates at 15 second intervals. On completion of the choice phase of the task, participants were presented with a list of all of the names and indicated those that they recognized prior to taking part in the experiment.

Materials and Design. A range of names selected from the Sunday Times Rich List 2005 were pretested for recognition. Names that were considered to carry intrinsic clues to wealth independent of recognition (e.g., "aristocratic-sounding" names) were excluded from the sample. On the basis of this pretest 60 pairs of names were constructed. The key pairs of names paired a name that elicited mid- to high-level recognition on pretesting with a name that pretesting identified as being unrecognized, despite the wealth of the individual concerned. The materials (see Appendix B) consisted of 40 pairs of names of this type, along with 20 pairs of filler items. Of the filler items, 10 pairs presented a highly recognized name with another highly recognized name, and 10 pairs presented an unrecognized name with another unrecognized name.

Results. 
Heuristic usage was calculated as in Experiment 1. Figure 2 shows stronger overall evidence for use of the recognition heuristic in this domain. For both the "richer" and the "poorer" frames, choices consistent with use of the recognition were made significantly more often than expected by chance $t=15.88, d f=39, p<0.001$ and $t=$ $12.64, d f=39, p<0.001$, respectively. Comparing the two groups, there was a small reduction of heuristic usage in the poorer framing (mean proportion heuristic usage $84 \%), t=1.63, d f=78, p=0.05$ (1-tailed), compared to the richer framing (mean proportion 89\%), indicating that the question framing once again influenced responding although to a lesser extent than previously.

\section{FIGURE TWO ABOUT HERE}

\section{Discussion}

As in Experiment 1, the results show that people are less likely to employ the recognition heuristic when asked a "lesser" question (in this case, who is poorer?) than when asked a "greater" question. The framing effect is weaker in the wealth domain however. Although there is a clear difference in choice behavior between "greater" and "lesser" frames, both produced recognition-based choices at a level greater than chance. One reason for this might be that recognition-based choices were close to ceiling in the standard (greater) framing for this domain, possibly because - in common parlance "rich" and "famous" are used as virtual synonyms. In the city task, recognizability and the size criterion are only indirectly related through a mediating variable such as the 
number of mentions in a news article. In the wealth task, causal connections can potentially be drawn - in either direction - between fame (recognizability) and fortune (criterion).

\section{Experiment 3.}

Experiment 3 applies a repeated measures design to the same questions as Experiments 1 and 2. It is possible that a decision-making 'set' might be established if the same decision (e.g., which of these towns is larger?) is faced repeatedly. Varying the decision question within-participants prevents the development of an artificial 'set' of this kind providing reassurance that the use (or failure to use) recognition-based inference is not simply the consequence of a mechanized "set effect" or Einstellung (Bilalić, McLeod \& Gobet, 2008; Luchins \& Luchins, 1958; McCloy, Beaman, Morgan $\&$ Speed, 2007). A repeated-measures design also enables us to examine the reliability of any observed individual differences in use of recognition-based inference. The study presented participants with post-experiment questions designed to identify their intuitions concerning the criterion-recognition relationship by asking them to judge the relative likelihood of recognizing items because they are large or not recognizing items because they are small. We anticipate that participants who believe they are more likely to recognize a town because it is large will show a stronger framing effect than participants who consider not recognizing a small town is as likely as recognizing a large town. This is because the former group are indicating a preference for inferring 
only that Large $(X)$ if Recognized $(X)$ whereas the latter group are additionally inferring that it is equally likely that Small $(Y)$ if $\neg$ Recognized $(Y)$.

Method

Participants. 72 participants (13 men, 59 women) with an average age of 23 years (range 18-67) volunteered to take part.

Materials and Design. Participants were presented with the town names from Experiment 1 and with a subsection of the names used in Experiment 2. Participants received 120 choice pairs, 60 pairs of town names and 60 pairs of names from the Rich List. For 30 of the town name pairs they were asked to identify the largest and for the other 30 pairs they were asked to identify the smallest town. Likewise, for the Rich List names they were asked to identify the richest person for half of the materials and the poorest for the other half. Presentation was blocked and counterbalanced. In two separate questions, administered subsequent to the choice tests, participants were asked to indicate what they thought was more likely a) they will recognize a town/person because it is big/they are rich, b) they will not recognize a town/person because it is small/they are poor, or c) the two options are equally likely.

Procedure. Participants were presented with an eight-page booklet. The four different types of judgment tasks were each presented on a separate page, the order of which was counterbalanced across participants. They were given 60 s to complete each task. On completion, they were asked the two likelihood questions which were followed by a 
request to indicate all of the names and towns they recognized prior to taking part in the experiment.

Results.

Choice Behavior. A repeated-measures ANOVA on the proportion of recognition heuristic usage with question frame and domain as within-participants factors shows main effects of frame, $F(1,70)=4.63, p=.035$, and domain; $F(1,70)=76.21, p<$ .001 , and a significant interaction between the two; $F(1,70) 7.16, p=.009$. Choice behavior was strongly consistent with the use of the recognition heuristic in the Rich List domain, $85 \%$ for the 'who is richest question' and $86 \%$ for the 'who is poorest' question $(t=16.38, d f=71, p<.001$, and $t=17.69, d f=70, p<.001$ respectively $)$. Choice behavior was overall consistent with use of the recognition heuristic in the city size domain, 69\% for the 'which town is largest' question and 57\% for the 'which town is smallest' question $(t=6.58, d f=71, p<.001$, and $t=2.21, d f=71, p=.03$ respectively). Paired samples t-tests confirmed a framing effect in the city size domain in that participants made more choices consistent with the recognition heuristic for the greater than the smaller frame, $t=3.19, d f=71, p=.002$, but no reliable framing effect in the Rich List domain, $t=-.14, d f=70, p=.89$. Figure 3 shows individual choice behavior for the city size task, and Figure 4 shows the same data for the wealth task.

FIGURE THREE ABOUT HERE 


\section{FIGURE FOUR ABOUT HERE}

\section{Individual Differences in Rated Likelihoods and the Use of Recognition. Many}

participants were willing to rate it equally likely that they would recognize a person because they are rich/ a town because it is large and they wouldn't recognize a person because they are poor/ don't recognize a town because it is small (Cities 43\%; Rich List $32 \%$ of participants). However, for those who did not consider the two probabilities equivalent, many rated it more likely that they would recognize an option due to size $(43 \%)$ or wealth $(57 \%)$. Few were willing to endorse the claim that they were less likely to recognize an item due to its lack of size or wealth (Cities 14\%; Rich List 11\%). A chi-square goodness of fit test revealed that judgments of the probabilities differed significantly both for the cities task; $\chi^{2}=12.25, \mathrm{df}=2, p=.002$, and for the rich list; $\chi^{2}$ $=22.75, \mathrm{df}=2, p<.001$, with the most popular choice overall being that it was more likely that they would recognize an item because it was large and the least popular being that it was more likely that they would fail to recognize an item because it was small. Participants' susceptibility to framing effects was related to their responses to these questions. Where we found an overall framing effect, in the Cities task, this was driven by those who believed that they were more likely to recognize a town because it was large. Broken down into groups, the framing effect - the difference between use of recognition in larger and smaller questions - was significant only for this group, $t=$ $3.34, d f=30, p=.002$, not for those who thought they were less likely to recognize a town because it was small $t=1.37, d f=9, p=.2$ (although this finding is statistically underpowered relative to the first comparison) or for those who thought both 
possibilities were equally as likely, $t=1.07, d f=30, p=.29$. The significant framing effect for this first group reflects difference reflects significantly higher use of recognition when asked the larger question than would be expected by chance, $t=5.91$, $d f=30, p<.001$ and use of recognition not significantly different from chance when asked the smaller question, $t=1.71, d f=30, p=.1$.

\section{Discussion.}

Experiment 3 again demonstrates a framing effect for the Cities task, although in this experiment use of recognition in the Wealth task was higher (near ceiling) and, perhaps in consequence, no framing effect was observed when that task was examined in isolation, although the main effect of frame remained significant across the domains. Post-hoc questioning revealed that reliably more participants were willing to state that recognition because of magnitude was more likely than lack of recognition because of lack of magnitude. Overall, more people in Experiment 3 endorsed unequal probabilities than were prepared to state that the two situations were equally likely. This pattern was identical for city size and wealth judgment tasks and is consistent with the observed framing effects and the hypothesis that greater and lesser questions invoke different cognitive processes associated with inferences made concerning the single recognized item. Importantly, a significant framing effect was only found amongst those participants who endorsed the idea that they were more likely to recognize a large item than to not recognize a small item. This finding confirms that the association between recognition and magnitude (or high value along a criterion) drives individuals to choose 
the recognized item whereas those same participants, if they do not associate lack of recognition with small magnitudes (or low values along a criterion), do not choose the unrecognized item significantly more than would be expected by chance if asked to indicate which option is the smallest.

\section{General Discussion}

To summarize, Experiments 1 and 2 demonstrated that question framing can alter usage of the recognition heuristic. People are less likely to use the heuristic when making judgments of which of two items has the least magnitude (smaller; poorer) than when judging which of two items has the greatest magnitude (larger; richer). Experiment 3 demonstrated that, overall, participants considered it to be intrinsically less plausible that they should fail to recognize an item because it is small than that they should recognize an item because of its size. This in itself implies a framing effect in recognition-driven judgment. Participants who showed this asymmetry in their rated intuitions of the relationship between the criterion and the recognition status of the item were the ones for whom a significant framing effect appeared in the Cities task. This suggests that recognition-driven choice in paired-choice tasks is based on inferences about the recognized item rather than reflecting a direct inference about the relationship between the paired items. The framing effect in Experiment 3 was limited to the Cities domain, however, and this may have been a consequence of a ceiling effect in the Wealth judgment task.

The current study shows how - in a similar manner to the original framing effect - logically equivalent forms can produce different behaviors (Kahneman \& Tversky, 
1979, 1984; Tversky \& Kahneman, 1981). A framing effect exists across logically equivalent choices, indicating that such choices are often informed by considering individual items rather than only making pair-wise comparisons. In recognition-based choice, such item-specific information is obviously more readily available for the recognized item of the pair. The relatively small framing effect observed in the Wealth domain in comparison to that seen in the Cities domain also indicates that domainspecific information contributes to nominally recognition-based decision-making. This "framing effect" differs from the classic framing observation, however, in that it reveals a reluctance to employ a particular (recognition-based) choice strategy when given a different framing rather than showing a wholesale switch-over in preference between two options. Other authors (e.g., Pachur \& Hertwig, 2006; Volz et al. 2006) have concluded that choosing the recognized item is the "default" choice rule and the current data are not inconsistent with this. However, if the inference rule for the use of recognition is item-based (Large $(X)$ if Recognized $(X))$ this accounts for the basic data on the recognition heuristic and its default status. As a default option, the choice rule is well-adapted to the environment if inferences are primarily concerned with identifying the highest-valued item along a criterion (e.g., the most promising sportsman, the bestperforming shares) rather than the lowest. Although we have no data on the relative frequency with which such decisions are made, it seems intuitively likely that high criterion judgments (the greater question) are required more often than low criterion judgments (the lesser question). 


\section{References}

Bennis, W. M., \& Pachur, T. (2006). Fast and frugal heuristics in sports. Psychology of Sport and Exercise, 7, 611-629.

Bilalić, M., McLeod, P., \& Gobet, F. (2008). Why good thoughts block better ones: The mechanism of the pernicious Einstellung (set) effect. Cognition, 108, 652-661.

Gigerenzer, G., \& Goldstein, D. G. (1996). Reasoning the fast and frugal way: Models of bounded rationality. Psychological Review, 103, 650-669.

Goldstein, D. G., \& Gigerenzer, G. (2002). Models of ecological rationality: The recognition heuristic. Psychological Review, 109, 75-90.

Grice, H. P. (1975). Logic and conversation. In: P. Cole \& J. Morgan (Ed.s). Syntax and semantics 3: Speech acts. pp. 41-58. New York: Academic Press.

Johnson-Laird, P. N., \& Shafir, E. (1993). The interaction between reasoning and decision making: An introduction. Cognition, 49, 1-9.

Kahneman, D., \& Tversky, A. (1979). Prospect theory: An analysis of decision under risk. Econometrica, 47, 263-291.

Kahneman, D., \& Tversky, A. (1984). Choices, values and frames. American Psychologist, 39, 341-350.

Kuhberger, A. (1995). The framing of decisions: A new look at old problems. Organizational Behavior and Human Decision Processes, 62, 230-240.

Kuhberger, A. (1998). The influence of framing on risky decisions. Organizational Behavior and Human Decision Processes, 75, 23-55.

Luchins, A. S., \& Luchins, E. H. (1959). Rigidity of behavior: A variational approach to the effects of Einstellung. Eugene: University of Oregon Press. 
McCloy, R., Beaman, C. P., Morgan, B. \& Speed, R. (2007). Training conditional and cumulative risk judgments: The role of frequencies, problem-structure and Einstellung. Applied Cognitive Psychology, 21, 325-344.

Oppenheimer, D. M. (2003). Not so fast! (and not so frugal!) Rethinking the recognition heuristic. Cognition, 90, B1-B9.

Pachur, T., \& Biele, G. (2007). Forecasting from ignorance: The use and usefulness of recognition in lay predictions of sports events. Acta Psychologica, 125, 99-116.

Pachur, T., \& Hertwig, R. (2006). On the psychology of the recognition heuristic: retrieval primacy as a key determinant of its use. Journal of Experimental Psychology: Learning, Memory \& Cognition, 32, 983-1002.

Serwe, S., \& Frings, C. (2006). Who will win Wimbledon? The recognition heuristic in predicting sports events. Journal of Behavioral Decision Making, 19, 321-332.

Sher, S., \& McKenzire, C. R. M. (2006). Information leakage from logically equivalent frames. Cognition, 101, 467-294.

Tversky, A., \& Kahneman, D. (1981). The framing of decisions and the psychology of choice. Science, 211, 453-458.

Volz, K. G., Schooler, L. J., Schubotz, R. I., Raab, M., Gigerenzer, G., \& von Cramon, D. Y. (2006). Why you think Milan is larger than Modena: Neural correlates of the recognition heuristic. Journal of Cognitive Neuroscience, 18, 1924-1936. 


\section{Author Note}

Parts of this research were supported by Leverhulme grant F/00 239/U to the first two authors and ESRC grant PTA-026-27-1688 to the third author. Caren Frosh is now at the School of Psychology, Queen's University Belfast. Correspondence concerning this article should be addressed to the first author at: School of Psychology \& Clinical Language Sciences, University of Reading, Earley Gate, Whiteknights, Reading RG6 6AL, United Kingdom. Email: r.a.mccloy@reading.ac.uk 


\section{Figure Captions.}

Figure 1. Proportion of responses per participant consistent with recognition-based inference. The upper panel represents the "larger" framing and the lower panel represents the "smaller" framing. Chance performance is .5 in both cases.

Figure 2. Proportion of responses per participant consistent with recognition-based inference. The upper panel represents the "richer" framing and the lower panel represents the "poorer" framing. Chance performance is .5 in both cases.

Figure 3. Proportion of responses per participant consistent with recognition-based inference in the city size task. The upper panel represents the "larger" framing and the lower panel represents the "smaller" framing. Chance performance is .5 in both cases

Figure 4 Proportion of responses per participant consistent with recognition-based inference in the wealth judgment task. The upper panel represents the "larger" framing and the lower panel represents the "smaller" framing. Chance performance is .5 in both cases 
FIGURE ONE
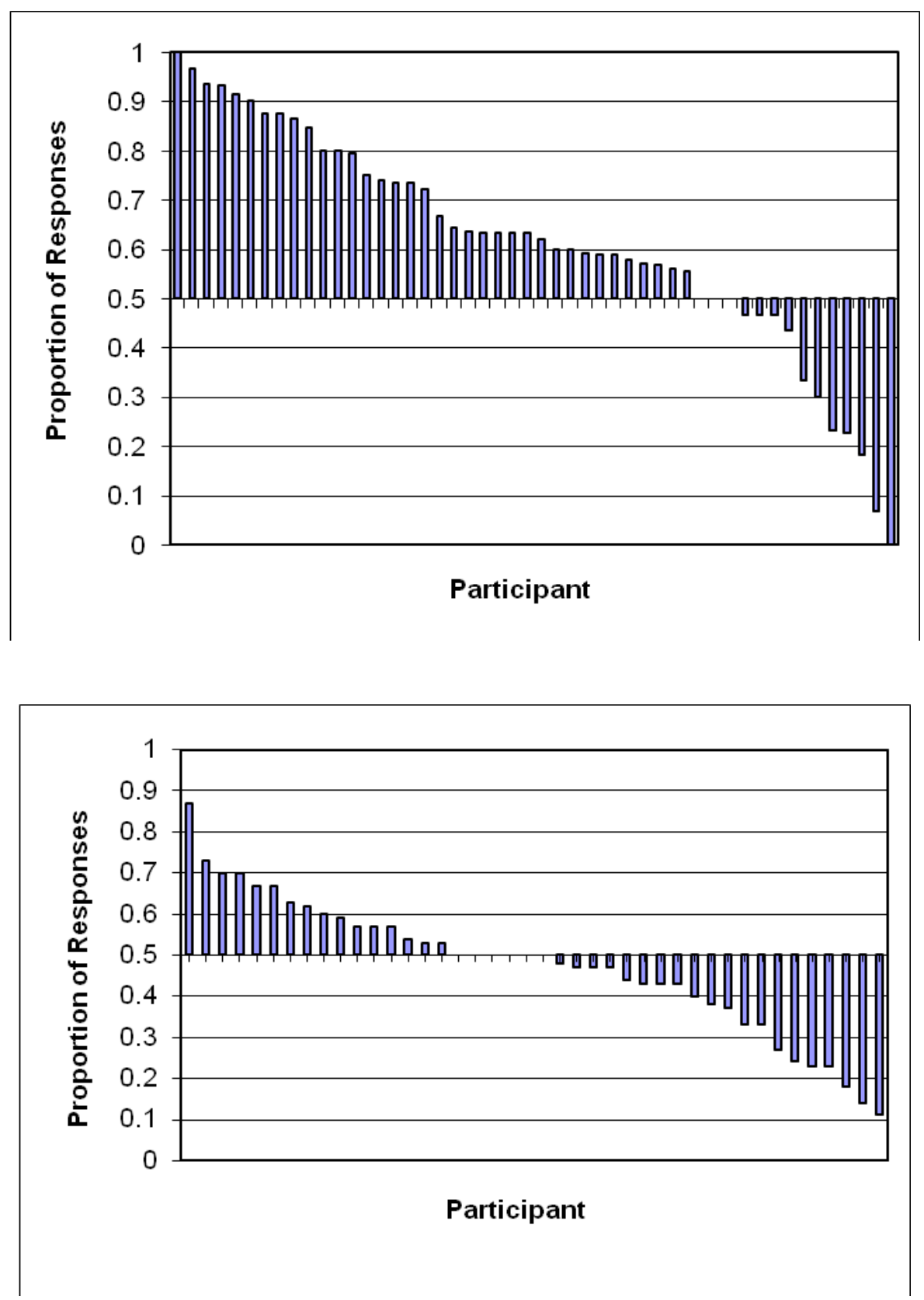

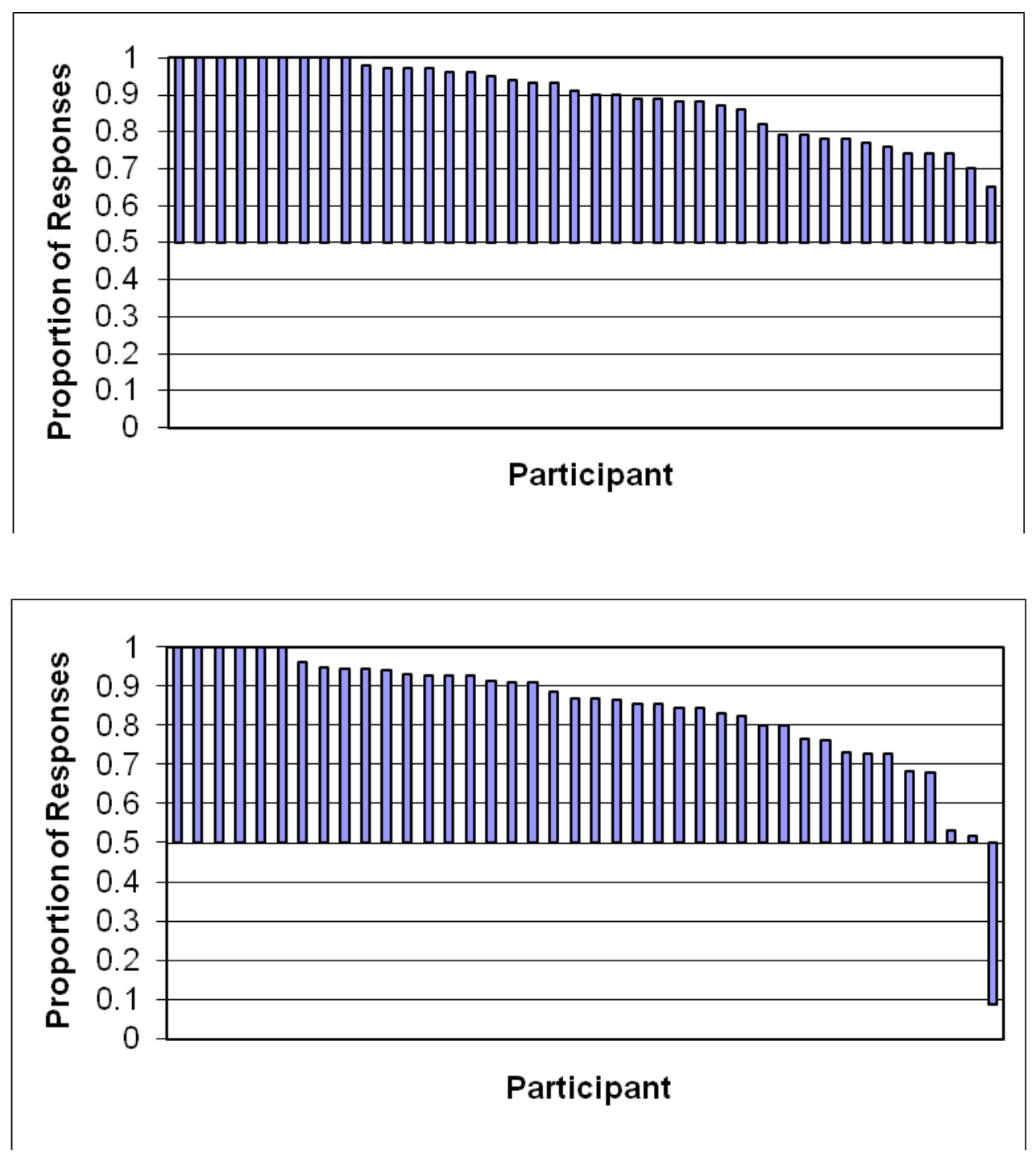
FIGURE THREE
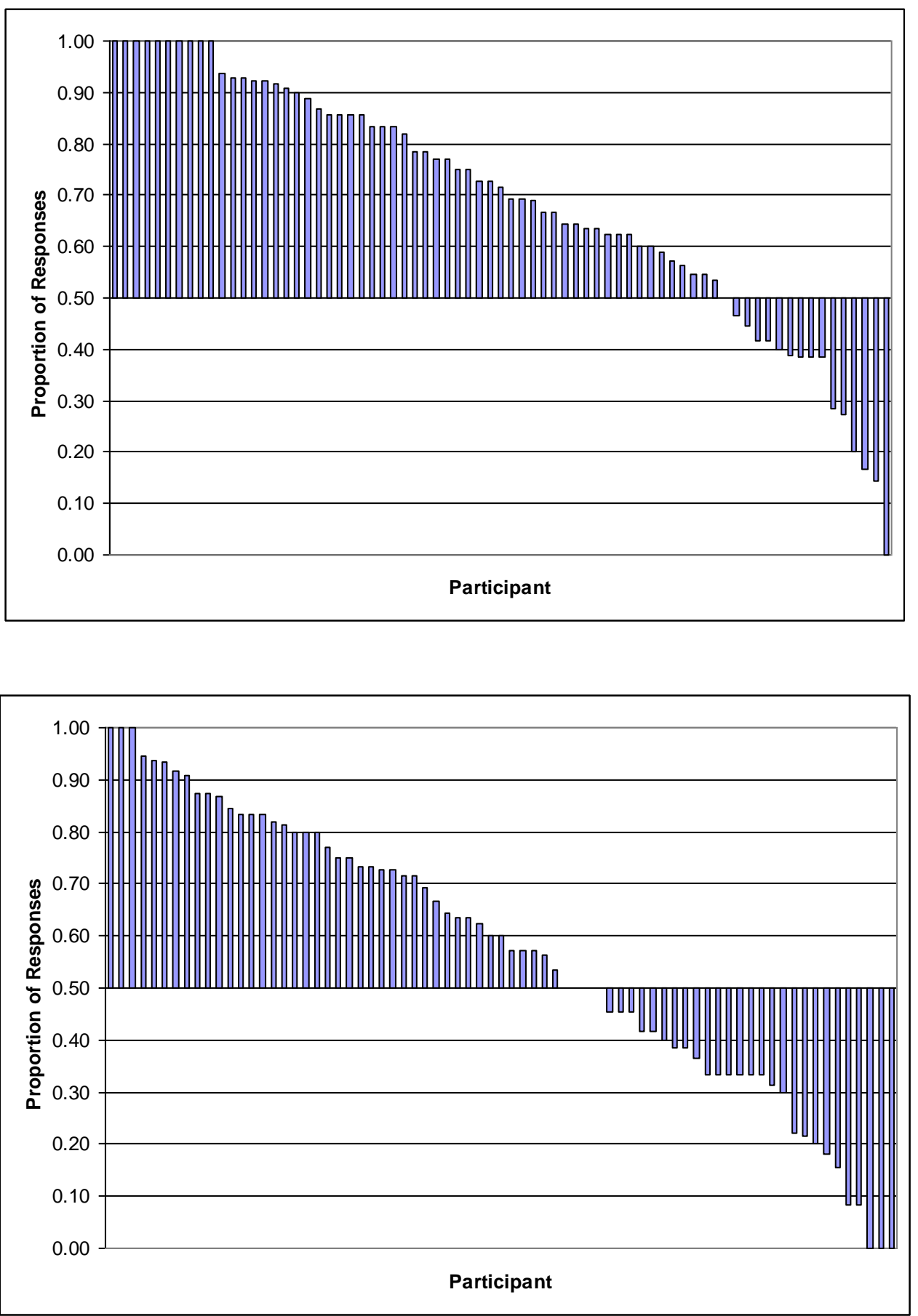
FIGURE FOUR
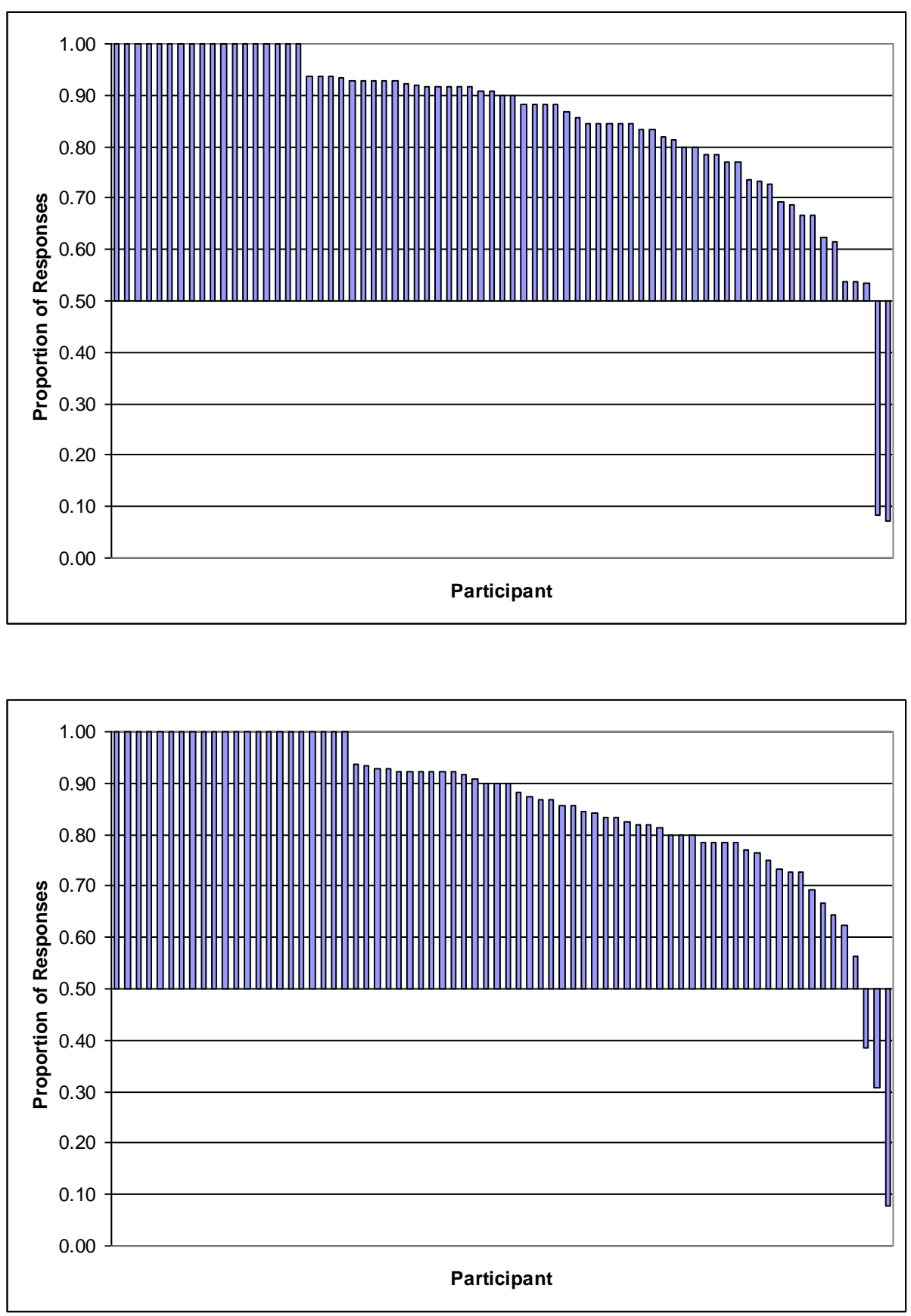


\section{Appendix A}

List of the towns and cities used as materials in the Cities task.

Fictional

Papayito

Al Ahbahib

Las Besas

Weingshe

Rio del Sol

Heingjing

Rhavadran

Gohaiza

Schretzberg

Svatlanov
Real

Norwich

Ipswich

Preston

Wigan

Sunderland

Crewe

Coventry

Gillingham

Sheffield

Burnley
Filler

Limerick

Toledo

Berkley

Haifa

Stoke

Rotherham

Bradford

Derby 
Appendix B

Sunday Times Rich List names used in Experiments $2 \& 3$. Wealth (in millions) as estimated in the 2005 Rich list is given in brackets after each name.

\begin{tabular}{|c|c|c|}
\hline Pamela Morgan Bell (110) & Chris Martin (10) & Trevor Baines (130) \\
\hline Simon Fuller (75) & Edward Macfarlane (6) & Tom Jones (175) \\
\hline Jackie Collins (66) & Damien Duff (8) & Kevin Stanford (80) \\
\hline Paul Marshall (100) & Nicky Butt (7) & Keith Richards (165) \\
\hline Anne Robinson (50) & Daniel Radcliffe (6) & John Frieda (180) \\
\hline Barbara Taylor Bradford (100) & Craig Pope (5) & Christopher Hohn (75) \\
\hline Eddie Irvine (153) & Sophie Dahl (5) & Carol Ainscow (40) \\
\hline Peter Hambro (75) & Mark Shuttleworth (170) & Harry Hyams (320) \\
\hline Lennox Lewis (100) & Bernard Matthews (316) & Mark Knopfler (65) \\
\hline Eric Clapton (130) & Rod Stewart (80) & Tom Wheatcroft (65) \\
\hline Robert Adair (172) & Rowan Atkinson (60) & Adrian Kirby (65) \\
\hline Judy Craymer (67) & Brian May (60) & Kathryn Sanders (5) \\
\hline Charlie Watts (80) & Michael Lemos (1100) & Geoffrey Elliot (60) \\
\hline Luke Johnson (80) & Alisa Marks (40) & Gareth Gates (5) \\
\hline Ronnie Wood (65) & Christopher Moran & Tony Pidgley (60) \\
\hline David Gilmour (75) & $(152)$ & \\
\hline Karen Millen (40) & Douglas Myers (130) & \\
\hline Will Champion (10) & Dean Allen (138) & \\
\hline Stephen Beetham (8) & James Dyson (1050) & \\
\hline James Berry (7) & Barrie Haigh (183) & \\
\hline
\end{tabular}

